\title{
Chemometric Analysis and Physicochemical Composition of Foreign and Tunisian Olive Oil: Consumer Preferences
}

\author{
Kaouther Ben-Hassine $\left(\mathbb{D},{ }^{1}\right.$ Islem Yangui $\mathbb{D}^{2},{ }^{2}$ Wissem Mnif $\mathbb{D}^{3,4}$ Ameni Taamalli $\left(\mathbb{D},{ }^{5}\right.$ \\ Cinzia Benincasa $(1),{ }^{6}$ Naziha Kamoun $\left(1,,^{7}\right.$ and Dhafer Malouche $\mathbb{1}^{8}$ \\ ${ }^{1}$ University of Carthage, High School of Agriculture Mograne LR03AGRO02 Research Laboratory of Agricultural \\ Production Systems and Sustainable Development, Tunis, Tunisia \\ ${ }^{2}$ University of Carthage, National Institute of Applied Science and Technology, UR17ES22, \\ Laboratory of Nanobiotechnology and Valorization of Medicinal Phytoresources, B.P. 676, Tunis 1080, Tunisia \\ ${ }^{3}$ Department of Chemistry, Faculty of Sciences and Arts in Balgarn, University of Bisha, P.O. Box 199, Bisha 61922, Saudi Arabia \\ ${ }^{4}$ University of Manouba, ISBST, BVBGR-LR11ES31, Biotechnopole Sidi Thabet, 2020 Ariana, Tunisia \\ ${ }^{5}$ Center of Biotechnology of Borj Cedria, Laboratoire de Biotechnologie de L'Olivier, Borj Cedria, Tunisia \\ ${ }^{6}$ CREA Research Centre for Olive, Fruit and Citrus Crops, C.da Li Rocchi, 87036 Rende, Cosenza, Italy \\ ${ }^{7}$ Institut de L'Olivier, Unité Technologie et Qualité, B.P. 1087, Sfax 3018, Tunisia \\ ${ }^{8}$ Engineering School of Statistics and Information Analysis, University of Carthage, Tunis, Tunisia
}

Correspondence should be addressed to Wissem Mnif; w_mnif@yahoo.fr

Received 21 September 2021; Revised 24 December 2021; Accepted 12 January 2022; Published 30 January 2022

Academic Editor: Francesco Genovese

Copyright $(2022$ Kaouther Ben-Hassine et al. This is an open access article distributed under the Creative Commons Attribution License, which permits unrestricted use, distribution, and reproduction in any medium, provided the original work is properly cited.

\begin{abstract}
This research was conducted to evaluate consumer preferences of seven extra virgin olive oils (EVOOs) from foreign and Tunisian cultivars. Two studies were carried out. The first is a comparative physicochemical characterization of the VOOs tasted by the consumers. The second is a consumer survey where each consumer tasted each VOO six times. Using simple linear regressions, we have performed a new method that gives a pairwise comparison between the oils. It revealed that Coratina and Chetoui cultivars were the most preferred revealing by the high concentration of polyphenols with 468 and $525 \mathrm{ppm}$, respectively, and Arbequina was the less preferred with $182 \mathrm{ppm}$. We have then performed a principal component analysis on the data composed by the physicochemical parameters that highly discriminate between cultivars. The latter showed important differences between the most and the less preferred oils and that oxidative stability, palmitic, palmitoleic, oleic, and linoleic fatty acids, triacylglycerol, $\beta$-carotene, and polyphenols seem to be the principal-choice drivers for consumers.
\end{abstract}

\section{Introduction}

Oleiculture is an important economic activity in Tunisia, which devotes $30 \%$ of its cultivated lands to olive growing. It corresponds to 1.7 million hectares. Tunisia is also ranked second after Spain contributing to $5.6 \%$ of the world production. Tunisia is also ranked fourth after Spain, Italy, and Greece. Tunisia's contribution represents $12 \%$ of the European market and $8.5 \%$ of the U.S. market. For a consumer, one of the most important characteristics in a product is for it to be fresh or recently made. Generally, the freshness of a product is associated with quality and therefore safety. This preference covers numerous aspects that are related to the cultivar of olive trees, their geographical sites, the technological process, the storage, the packaging, and the physicochemical and sensory characteristics of olive oil. Tunisian consumers have always been accustomed to the consumption of olive oil since olive cultivation in Tunisia dates back to the 8 th century B.C. The olive tree was cultivated by the Phoenicians, the Greeks, the Carthaginians, the Romans, and the Arabs, in a tradition that has been passed down from father to son ever since. Olive oil is characterized by a 
TABLE 1: Distribution of the consumers by age group, gender, region of origin, and frequency of consumption of VOO.

\begin{tabular}{lccc}
\hline Age & FC & Gender & RO \\
\hline 1 youth: 121 & $1: 204$ & F: 62 & Center: 42 \\
2 adults: 153 & $2: 42$ & M: 212 & North: 106 \\
& $3: 21$ & & Sahel: 91 \\
& $4: 7$ & & South: 35 \\
\hline
\end{tabular}

FC: frequency of consumption. RO: region of origin.

delicate and unique flavor highly appreciated by consumers. It has also attracted the consumers because of its nutritional content and its medical virtues. There have been several studies that were concerned with olive oil cultivar in terms of the physicochemical and sensory characterization $[1,2]$. Few, however, were concerned with the evaluation of olive oil in terms of its consumer and their preference. The applicability of the results is debatable as the consumers' capacity and knowledge level to distinguish between the olive oil varieties is unknown for us. Therefore, the present paper focuses on the consumer preferences of seven Tunisian and foreign virgin olive oil cultivars, Chemlali, Chetoui, Leguim, Chemcheli, Zalmati, Arbequina, and Coratina, according to their liking and physicochemical profiles. We give a new approach that can be used to make a pairwise comparison between these VOO cultivars and then to be able to determine the most preferred virgin olive oil (VOO) cultivars.

\section{Materials and Methods}

2.1. Products. Consumer tests were conducted on 7 samples of $\mathrm{VOO}$ in order to explore the consumer preferences in function of some Tunisian and foreign VOOs cultivar and to explain this preference with the liking and analytical parameters of the oils. Olives from seven cultivars, Chemlali, Chetoui, Leguim, Chemcheli, Zalmati, Arbequina, and Coratina, that are used in this study were collected at the same ripeness stage when the fruit skin was light violet in color $(3<\mathrm{RI}<4)$, and oil extraction was carried out using continuous three-phase centrifugation system at $28^{\circ} \mathrm{C}$ with malaxation for $60 \mathrm{~min}$ at experimental olive mill of Institute of Sfax. The obtained VOOs were put in different dark glass bottles of $250 \mathrm{~mL}$ and stored at $16^{\circ} \mathrm{C}$ until further use. During the session, the samples were served in plastic glasses coded with 3-digit numbers. The amount of each sample served to taste was $20 \mathrm{~mL}$ with no obligation to finish the glass.

2.2. Subjects. Two hundred and seventy-four consumers took part in the study. Table 1 gives the distribution of the consumers by age, gender, frequency of olive oil consumption (FC), and geographical origin groups (RO). Regarding the $\mathrm{RO}$, there are also four groups which range from the north to the south. Some of the consumers are from the northern region; an important population is from the Sahel region while almost half of the sample comes from the south.
Out of a panel of 274 consumers, $75 \%$ consume the olive oil on a daily basis, $14 \%$ consume olive oil once a week, $7 \%$ consume olive oil once in a month, and $4 \%$ do not like olive oil at all.

2.3. General Design. Six sessions were organized for three weeks. For each session, the same consumers have tasted the seven VOOs. Each VOO was presented 6 times in order to obtain consistent statistical results. All the sessions took place in a training center of BTS (Brevet Superior Technician) specialized in food agriculture. The sessions were held once a day and last approximately half an hour. Data were collected on a paper questionnaire. The order of presentation of the samples was randomized after each test. The sensory evaluations were conducted in a suitably lighted room equipped with boots, separated from any source of noise and equipped with air conditioning to keep a temperature of about $20-25^{\circ} \mathrm{C}$, according to the COI/T.20/Doc. No. 6/Rev.1 [3].

2.4. Tasting Description. During the test, consumer rinses their mouth using water or a piece of apple between each VOO sample. For each product, consumers had to rate their hedonic judgment using the labels "I like" and the other "I do not like." The hedonic ratings were then translated into scores ranging from 0 to 20 .

2.5. Consumer Questionnaire. Each consumer had to fill in a questionnaire concerning sociodemographic information (age, gender, FC, and RO).

2.6. Quality Indices. Free acidity, peroxide value (IP), and UV spectrophotometric indices (at 232 and $270 \mathrm{~nm}$ ) were determined according to ISO procedures (ISO 660:1996; ISO 3960: 2001) and the International Olive Council (IOC) standard (IOC 2013), respectively $[4,5,6]$.

2.7. Oxidative Stability. Induction time was measured with a 743 Rancimat instrument (Metrohm Switzerland) using an oil sample of $3 \mathrm{~g}$ warmed at $120^{\circ} \mathrm{C}$ and in a $20 \mathrm{~L} / \mathrm{h}$ air flow [7]. The results were expressed in hours.

2.8. Pigment Contents. Chlorophyll and carotenoid were calculated from the absorption spectra of each virgin olive oil sample $(7.5 \mathrm{~g})$ dissolved in cyclohexane $(25 \mathrm{~mL})$ following the method of Minguez-Mosquera and coworkers [8]. The maximum absorption at $670 \mathrm{~nm}$ is related to the chlorophyll fraction and at $470 \mathrm{~nm}$ is related to carotenoid fraction. The values of the coefficients of specific extinction applied were $E 0=613$ for pheophytin as a major component in the chlorophyll fraction and $E 0=2000$ for lutein as a major component in the carotenoid fraction. 
2.9. Fatty Acid Composition. In order to determine fatty acid composition (\%), the methyl esters were prepared by vigorous shaking of a solution of oil in hexane $(0.1 \mathrm{~g}$ in $2 \mathrm{~mL})$ with $0.2 \mathrm{~mL}$ of $2 \mathrm{~N}$ methanolic potassium hydroxide solution and analyzed by GC with a Hewlett-Packard (HP 5890) chromatograph equipped with an FID detector. A fused silica column, HP-INNOWax $(30 \mathrm{~m} \times 0.25 \mathrm{~mm}$, i.d. $0.25 \mu \mathrm{m}$ ), was used. Nitrogen was employed as a carrier gas, with a flow rate of $1 \mathrm{~mL} / \mathrm{min}$. The temperatures of the injector and detector were set at 250 and $270^{\circ} \mathrm{C}$, respectively. An injection volume of $1 \mu \mathrm{L}$ was used. The operating conditions were as follows: oven temperature was held at $180^{\circ} \mathrm{C}$ for $1 \mathrm{~min}$ and then increased by $10^{\circ} \mathrm{C} \mathrm{min}{ }^{-1}$ to $220^{\circ} \mathrm{C}$, held for $1 \mathrm{~min}$ at $220^{\circ} \mathrm{C}$, increased again to $240^{\circ} \mathrm{C}$ at $2^{\circ} \mathrm{C} \mathrm{min}{ }^{-1}$, and finally isotherm at $240^{\circ} \mathrm{C}$ for $1 \mathrm{~min}$. Fatty acids were identified from their retention times compared to those of standard compounds. Results were expressed as percent of relative area [9].

2.10. Triacylglycerol Composition. Oils were separated by high-performance liquid chromatography (HPLC) equipped with a reverse phase C18 column $(5 \mathrm{~mm} ; 4.60 \times 250 \mathrm{~mm}$, Waters Associates, Milford, MA, USA). The eluent was monitored by refractive index detector. The mobile phase was acetone/acetonitrile $(60: 40, \mathrm{v} / \mathrm{v})$ with a flow rate of $1.50 \mathrm{~mL} / \mathrm{min}$. All solvents were of HPLC grade. Samples $(5 \mu \mathrm{L})$ were prepared by dissolving the oil in acetone $(9: 91$, $\mathrm{v} / \mathrm{v})$. Peak assignment was carried out by comparison with chromatograms and with the retention times of some pure standards [10].

2.11. Phenolic Composition. The phenolic compounds were firstly extracted by liquid-liquid extraction and then analyzed according to the method of Montedoro and coworkers [11]. Briefly, the phenolic composition was carried out using a Varian 5000 chromatograph with a $160 \mathrm{~mm} \times 4.6 \mathrm{~mm}$ C18 Erbasil column, coupled with a Varian PolyChrom 9060 UV photodiode spectrophotometer. The eluates were detected at 278 and $239 \mathrm{~nm}$ at $25^{\circ} \mathrm{C}$. The mobile phase was composed of $2 \%$ acetic acid ( $\mathrm{pH} 3.1$ ) in water (solvent $\mathrm{A}$ ) and methanol (solvent $\mathrm{B}$ ) for a total running time of $45 \mathrm{~min}$ at a flow rate of $1 \mathrm{~mL} / \mathrm{min}$, with the following gradient: $95 \% \mathrm{~A} / 5 \% \mathrm{~B}$ for $2 \mathrm{~min}, 75 \% \mathrm{~A} / 25 \% \mathrm{~B}$ in $8 \mathrm{~min}, 60 \% \mathrm{~A} / 40 \% \mathrm{~B}$ in $10 \mathrm{~min}, 60 \% \mathrm{~A} / 50 \% \mathrm{~B}$ in $10 \mathrm{~min}$, and $0 \% \mathrm{~A} / 100 \% \mathrm{~B}$ in $10 \mathrm{~min}$ until the end of running. Phenolic extracts were dissolved in methanol, and $10 \mu \mathrm{L}$ of this solution was injected into the column.

\section{Data Analysis}

In this study, we have constructed two data sets: the first is about the results of the physicochemical parameters and the second is about the consumer preference.

3.1. Analyzing Physicochemical Parameters. In this part, we have mainly been interested in the effect of the cultivar factor on all the physicochemical parameters. First, we performed a one-way analysis of variance (ANOVA, Tukey's honest significant difference multiple comparison) using the agricolae package (version 1.1-22) in the $\mathrm{R}$ software (version 2.15.33) which is a set of statistical procedures for agricultural research. Then, after considering only the parameters having a significant relation with the variable "cultivar" and are able to discriminate between at least three varieties, we have calculated their correlation matrix and represented it by a correlogram (dotted line). Finally, we have standardized these variables and used them to perform Principal Component Analysis (PCA). Indeed, the variable "cultivar" was considered in this PCA as supplementary factor variable, and we have used the coordinates of the varieties on the first two principal components for the cluster analysis. This later statistical analysis is performed using the package MASS4 in the R software (version 2.15.3).

3.2. Consumer Preference Analysis. Two hundred seventyfour consumers participated in the study, where a questionnaire was carried out. Each consumer tasted VOO six times from each cultivar. Hence, for each consumer, we have 42 liking scores. The most common way to analyze preference consumers is to construct internal or external preference mapping $[12,13]$. In the internal preference mapping, a PCA is performed on preference data where observations or rows are the products. The variables or columns are the consumers. A biplot of the products and the consumers has been drawn. In the external preference mapping, we try to relate the preferences scores given by the consumers to some other variables measured on the product, such as physicochemical, sensory parameters, and different kinds of external descriptors of the products. These methods consist first of performing a PCA on the external descriptors of the products, and we apply for each consumer a regression model according to a particular linked function of the principal components used to describe the products.

In our case, we have only seven different products; each one corresponds to a different cultivar of VOO, and this number is not enough to be able to perform neither an internal preference mapping, nor an external one. We have created, for the first time, a mild and operationally simple method that allows getting a pairwise comparison between our products and then we will show how we will be able to declare the most preferred cultivar for our consumers.

Let us notice that for a given pair of differences for tasting two VOO products from two different cultivars, let us call them $v$ and $v^{\prime}$, we have three disjoint groups of consumers:

(i) Group 1: consumers who are not able to make difference between $v$ and $v^{\prime}$

(ii) Group 2: consumers who prefer $v$ to $v^{\prime}$

(iii) Group 3: consumers who prefer $v^{\prime}$ to $\mathrm{v}$

The main idea behind our method is to estimate the cardinality of each group, especially we will be interested in groups 2 and 3 and we will compute the difference between these two cardinalities of Groups 2 and 3: 
TABLE 2: Quality indices, oxidative stability, and pigment contents of the seven VOOs.

\begin{tabular}{|c|c|c|c|c|c|c|c|}
\hline & $\begin{array}{c}\text { Free acidity } \\
(\% \mathrm{C} 18: 1)\end{array}$ & K232 & K270 & IP (MeqO2/kg) & O.S (h) & Chlorophyll (ppm) & $\begin{array}{c}\text { Carotenoids } \\
(\mathrm{ppm})\end{array}$ \\
\hline Arbequina & $0.28 \pm 0.10 \mathrm{a}$ & $1.50 \pm 0.16 a$ & $0.14 \pm 0.05 a$ & $11.17 \pm 0.92 \mathrm{a}$ & $3.81 \pm 0.42 b$ & $3.37 \pm 1.55 \mathrm{a}, \mathrm{b}, \mathrm{c}$ & $2.92 \pm 0.92 \mathrm{a}, \mathrm{b}$ \\
\hline Chemcheli & $0.36 \pm 0.07 a$ & $1.60 \pm 0.21 \mathrm{a}$ & $0.20 \pm 0.01 \mathrm{a}$ & $10.33 \pm 0.83 a$ & $8.49 \pm 1.00 \mathrm{~b}$ & $4.31 \pm 0.60 \mathrm{a}, \mathrm{b}$ & $3.35 \pm 0.71 \mathrm{a}, \mathrm{b}$ \\
\hline Chemleli & $0.62 \pm 0.28 \mathrm{a}$ & $1.78 \pm 0.26 a$ & $0.11 \pm 0.00 \mathrm{a}$ & $10.73 \pm 1.07 \mathrm{a}$ & $4.56 \pm 0.71 b$ & $1.68 \pm 0.39 c$ & $2.82 \pm 2.59 \mathrm{a}, \mathrm{b}$ \\
\hline Chetoui & $0.62 \pm 0.29 a$ & $1.87 \pm 0.20 \mathrm{a}$ & $0.20 \pm 0.01 \mathrm{a}$ & $12.40 \pm 1.61 \mathrm{a}$ & $8.38 \pm 1.97 b$ & $5.82 \pm 0.43 a$ & $5.26 \pm 0.02 \mathrm{a}$ \\
\hline Coratina & $0.22 \pm 0.05 a$ & $1.97 \pm 0.04 \mathrm{a}$ & $0.18 \pm 0.02 \mathrm{a}$ & $7.47 \pm 1.37 \mathrm{a}$ & $14.07 \pm 0.90 \mathrm{a}$ & $1.80 \pm 0.11 \mathrm{c}$ & $0.13 \pm 0.01 b$ \\
\hline Leguim & $0.70 \pm 0.36 \mathrm{a}$ & $1.72 \pm 0.31 \mathrm{a}$ & $0.11 \pm 0.02 \mathrm{a}$ & $12.87 \pm 1.21 \mathrm{a}$ & $4.74 \pm 0.16 b$ & $4.91 \pm 0.7 \mathrm{a}$ & $1.82 \pm 0.17 \mathrm{a}, \mathrm{b}$ \\
\hline Zalmati & $0.50 \pm 0.14 \mathrm{a}$ & $1.19 \pm 0.16 \mathrm{a}$ & $0.08 \pm 0.01 \mathrm{a}$ & $11.13 \pm 1.21 \mathrm{a}$ & $4.00 \pm 0.43 b$ & $2.44 \pm 0.31 b, c$ & $0.65 \pm 0.52 a, b$ \\
\hline
\end{tabular}

Mean values in the same column with the same letter are not significantly different between cultivars.

$\Delta\left(v-v^{\prime}\right)=\operatorname{I}$ Group $2\left(v-v^{\prime}\right) \mathrm{I}-\mathrm{I}$ Group $3\left(v-v^{\prime}\right) \mathrm{I}$.

So, the more $\Delta\left(v, v^{\prime}\right)$ is positive, the more we can say that $v$ is preferred to $v^{\prime}$. The question is how to proceed to estimate this difference $\Delta\left(v, v^{\prime}\right)$. Indeed, a positive value for $\Delta$ $\left(v, v^{\prime}\right)$ indicates that $v$ is preferred to $v^{\prime}$ and when it is negative, $v^{\prime}$ is then preferred to $v . \Delta\left(v, v^{\prime}\right)$ can be then considered as an indicator of the pairwise preference between the cultivars $v$ and $v^{\prime}$.

We suggest then to perform several linear regression models (or one-way ANOVA). Since each consumer has tasted 6 times each cultivar, so for each one, we have a vector of 42 preference scores. We fixed first one of the cultivars, in our case Arbequina cultivar. We performed a simple linear regression analysis where the response variable is the vector of preference scores of one consumer and where the explained variable is the factor "curltivar." We obtain then six $\beta$ coefficients. Each one corresponds to the six remaining cultivars. It is known that by default the seventh $\beta$ coefficient corresponding to Arbequina cultivar is set to be equal to zero. When an estimated $\beta$ is significantly positive $(p<0.05)$, we can declare that this consumer prefers the corresponding cultivar to the Arbequina cultivar. We repeated this procedure for all the consumers and we have then an estimation of the $\Delta$ defined in equation (1) for a fixed cultivar, that is, Arbequina, compared to the others. We changed then the reference cultivar to another one and we did again exactly the same technique described above. We continued until we obtained two sets of $(7 \times 6)$ pairs of $\Delta$ numbers, each one indicating how our consumers prefer one cultivar to another one. We obtained then a $(7 \times 7)$ matrix where the rows and the columns correspond to the seven cultivars and where one entry of the matrix indicates the number $\Delta$ defined in equation (1), which is the difference between the number of consumers that prefer significantly the cultivar in the column compared to that one in the row with the number of them who prefer the cultivar in row comparing to the one in the column. The direction of the ellipse in each cell corresponds to the sign of the corresponding difference. Increase direction means that there are more consumers who prefer the cultivar in the column than the one in a row. Decreasing direction shows the other case. We have also chosen white fonts to represent negative differences and black fonts to represent positive differences.

\section{Results and Discussion}

4.1. Characterization of VOOs. Table 2 shows the physicochemical quality parameters of olive oil from the studied cultivars. The values of the quality parameters were comprised within the ranges established for "extra virgin olive oil" (EVOO) category for all the oils. At the sensory analysis, acidity is considered an important quality index, which has been exclusively used as a traditional criterion for classifying olive oil. The percentage of free acidity (Table 1) did not exceed the upper limit of $0.8 \%$ established by the IOOC norm and corresponding to the EVOO class. The lowest value was found for Chetoui with $0.25 \%$ while for the oil obtained from Oueslati it was higher $(0.83 \%)$. The values of the quality parameters were comprised within the ranges established for "extra virgin olive oil" (EVOO) category for all the oils. The PV values, $\mathrm{K}_{232}$, and $\mathrm{K}_{270}$ were confirmed as $\leq 20$ meq O2 kg-1, $\leq 2.5$, and $\leq 0.22$, respectively, for EVOO classification. These results showed that the cultivar had no significant influence on these analytical parameters, which are indicative of damage inflicted up on the fruits. Another important parameter of olive oil quality that was evaluated in our work is the oxidative stability (OS) measured as induction time determined using the Rancimat method. The registered values of OS varied significantly between VOOs cultivars $(p<0.05)$ from $4.05 \mathrm{~h}$ for Zalmati VOO to $15.66 \mathrm{~h}$ for Chetoui VOO being the most stable followed by Coratina $13.89 \mathrm{~h}$. These results are in agreement with those reported by Benincasa and coworkers [14]. The correlation matrix presented in Figure 1 reveals the existence of groups of variables. Those corresponding to blue cells are negatively correlated and those corresponding to yellow cells are positively correlated. Figure 1 showed a negative correlation between OS, IP and free acidity values. This result is not in accordance with the reported literature of Issaoui and coworkers [13]. A positive correlation is observed between OS and $\mathrm{K}_{270}$ as reported also in Issaoui and coworkers [15]. Color is an important attribute for the determination of olive oil characteristics and is related to the quality for the majority of consumers. This attribute is directly related to the olive oil pigment content (chlorophyll and carotenoids). In the analyzed oils, significant differences were found according to the cultivar $(p<0.05)$ (Table 2). Chlorophyll contents ranged between 2.35 (Zalmati) and $6.61 \mathrm{ppm}$ (Coratina). The carotenoids contents ranged between 0.91 (Zalmati) and $5.29 \mathrm{ppm}$ (Coratina). 


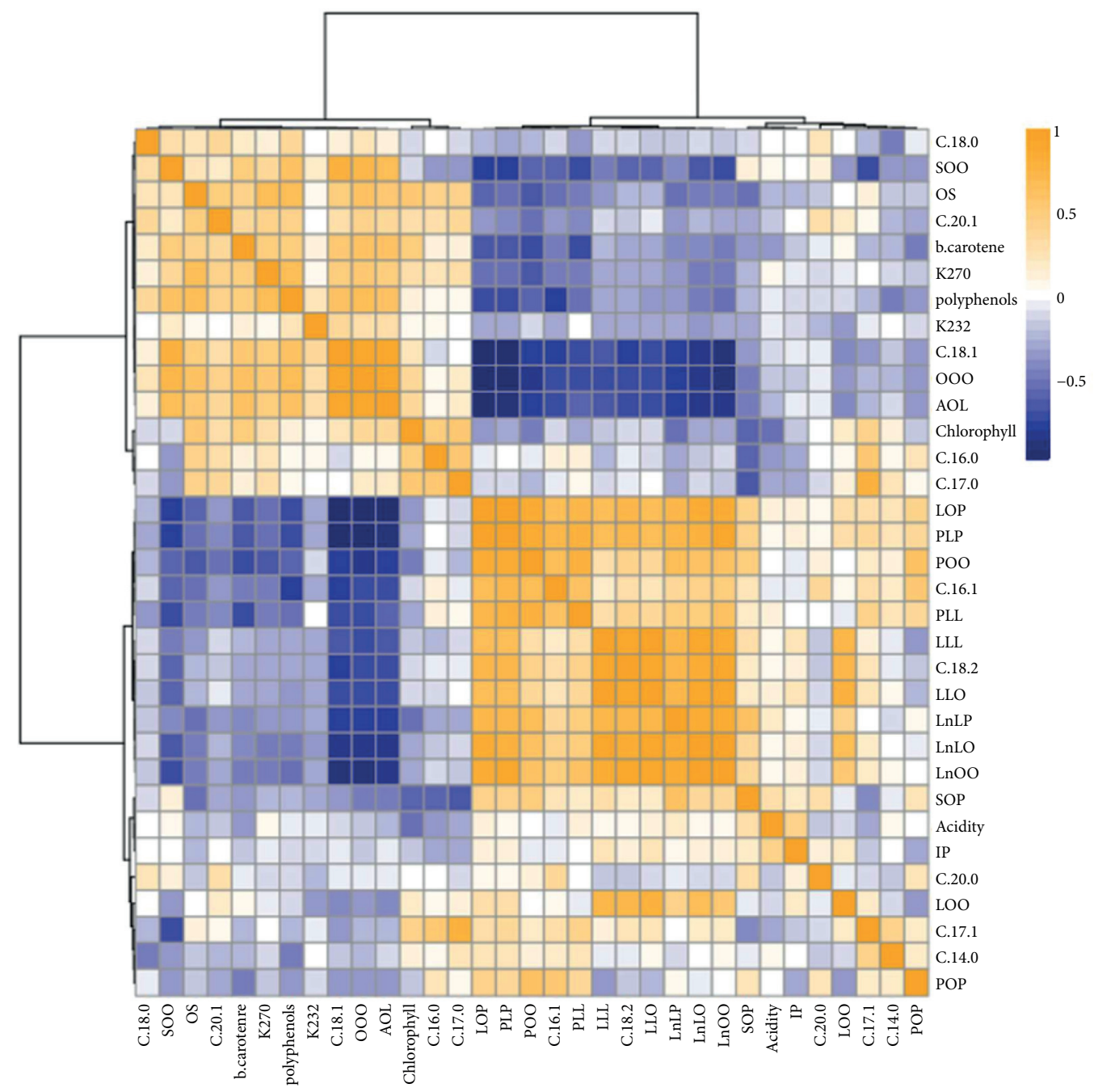

FIGURE 1: Representation of the correlations between the physicochemical parameters which highly discriminate between cultivars.

TABLe 3: Fatty acid composition of the seven VOOs.

\begin{tabular}{|c|c|c|c|c|c|c|c|}
\hline Fatty acid (\%) & Arbequina & Chemcheli & Chemleli & Chetoui & Coratina & Leguim & Zalmati \\
\hline C14:0 & $0.01 \pm 0.001 \mathrm{a}$ & $0.01 \pm 0.00 \mathrm{a}$ & $0.01 \pm 0.00 \mathrm{a}$ & $0.01 \pm 0.001 \mathrm{a}$ & $0.01 \pm 0.01 \mathrm{a}$ & $0.01 \pm 0.00 \mathrm{a}$ & $0.01 \pm 0.00 \mathrm{a}$ \\
\hline $\mathrm{C} 16: 0$ & $14.70 \pm 0.67 \mathrm{a}, \mathrm{b}$ & $13.47 \pm 0.31 b$ & $15.62 \pm 0.20 \mathrm{a}, \mathrm{b}$ & $9.39 \pm 0.40 c$ & $10.71 \pm 0.58 c$ & $10.68 \pm 0.79 c$ & $16.08 \pm 0.12 \mathrm{a}$ \\
\hline $\mathrm{C} 16: 1$ & $1.77 \pm 0.11 \mathrm{a}, \mathrm{b}$ & $1.20 \pm 0.16 b, c$ & $2.02 \pm 0.07 \mathrm{a}$ & $0.47 \pm 0.05 c$ & $0.52 \pm 0.05 c$ & $1.18 \pm 0.36 b, c$ & $1.99 \pm 0.06 a$ \\
\hline $\mathrm{C} 17: 0$ & $0.08 \pm 0.006 a$ & $0.06 \pm 0.003 c$ & $0.05 \pm 0.01 \mathrm{a}, \mathrm{b}$ & $0.04 \pm 0.003 b, c$ & $0.04 \pm$ & $0.04 \pm 0.00 c$ & $0.04 \pm 0.002 c$ \\
\hline $\mathrm{C} 17: 1$ & $0.16 \pm 0.01 \mathrm{a}$ & $0.06 \pm 0.005 b$ & $0.08 \pm 0.003 b$ & $0.07 \pm 0.005 b$ & $0.08 \pm$ & $0.06 \pm 0.003 b$ & $0.07 \pm 0.00 b$ \\
\hline $\mathrm{C} 18: 0$ & $1.94 \pm 0.10 c$ & $2.73 \pm 0.06 a$ & $2.37 \pm 0.04 b$ & $2.75 \pm 0.10 \mathrm{a}$ & $2.43 \pm 0.06 a, b$ & $2.68 \pm 0.09 \mathrm{a}, \mathrm{b}$ & $2.44 \pm 0.02 \mathrm{a}, \mathrm{b}$ \\
\hline $\mathrm{C} 18: 1$ & $66.30 \pm 0.73 c$ & $68.24 \pm 0.69 b, c$ & $60.77 \pm 0.53 \mathrm{~d}$ & $69.05 \pm 1.05 b, c$ & $76.79 \pm 1.42 \mathrm{a}$ & $72.07 \pm 1.75 a, b$ & $60.40 \pm 0.59 \mathrm{~d}$ \\
\hline $\mathrm{C} 18: 2$ & $13.69 \pm 0.65 b, c$ & $12.68 \pm 0.56 c$ & 17.65 & $16.45 \pm 1.05 \mathrm{a}, \mathrm{b}$ & $7.83 \pm 0.78 \mathrm{~d}$ & $11.73 \pm$ & 17.33 \\
\hline $\mathrm{C} 18: 3$ & $0.72 \pm 0.13 a$ & $0.59 \pm 0.09 a$ & $0.62 \pm 0.01 \mathrm{a}$ & $0.86 \pm 0.15 a$ & $0.72 \pm 0.01 \mathrm{a}$ & $0.62 \pm 0.5 \mathrm{a}$ & $0.69 \pm 0.06 a$ \\
\hline $\mathrm{C} 20: 0$ & $0.33 \pm 0.18 \mathrm{a}$ & $0.53 \pm 0.02 \mathrm{a}$ & $0.52 \pm 0.05 a$ & $0.33 \pm 0.16 \mathrm{a}$ & $0.42 \pm 0.004 a$ & $0.47 \pm 0.003 a$ & $0.48 \pm 0.01 \mathrm{a}$ \\
\hline $\mathrm{C} 20: 1$ & $0.26 \pm 0.06 b, c$ & $0.31 \pm 0.01 \mathrm{a}, \mathrm{b}, \mathrm{c}$ & $0.22 \pm 0.008 c$ & $0.41 \pm 0.02 \mathrm{a}$ & $0.37 \pm 0.02 \mathrm{a}, \mathrm{b}$ & $0.36 \pm 0.02 \mathrm{a}, \mathrm{b}$ & $0.23 \pm 0.007 \mathrm{c}$ \\
\hline
\end{tabular}

Mean values in the same row with the same letter are not significantly different between cultivars.

Analysis of variance showed a significant effect of cultivar $(p<0.05)$ on VOO pigments. This result is in accordance with the study by Issaoui and coworkers [15]. Data in Figure 1 showed that chlorophyll content was highly negatively correlated with free acidity and the minor TAG SOP. Results showed also a negative correlation between chlolorophyll and LnLO, LnLP, POO, and LnOO. However, chlorophyll amount was poorly negatively correlated with IP. Regarding carotene, Figure 1 showed a highly negative correlation with the major TAG, LOP. However, carotene was positively correlated with C18:1, polyphenols, $\mathrm{K}_{270}$, and OS. 
TABLE 4: Triacylglycerol composition of the seven VOOs.

\begin{tabular}{|c|c|c|c|c|c|c|c|}
\hline TAG (\%) & Arbequina & Chemcheli & Chemleli & Chetoui & Coratina & Leguim & Zalmati \\
\hline LLL & $0.24 \pm 0.02 a, b, c$ & $0.20 \pm 0.029 c$ & $0.47 \pm 0.03 a, b$ & $0.50 \pm 0.10 \mathrm{a}$ & $0.03 \pm 0.007 c$ & $0.22 \pm 0.03 b, c$ & $0.49 \pm 0.08 \mathrm{a}, \mathrm{b}$ \\
\hline LnLO & & 0.32 & 6 a & $0.40 \pm$ & $07 \mathrm{c}$ & 0.30 & $02 a$ \\
\hline LnLP & $0.08 \pm 0.02 c, d$ & $0.11 \pm 0.01 b, c$ & $0.15 \pm 0$ & $0.09 \pm 0$ & $0.04 \pm$ & $0.07 \pm$ & $.006 \mathrm{a}$ \\
\hline LLO & $4.50 \pm$ & & $1 \mathrm{a}, \mathrm{b}$ & & & $3.51 \pm$ & $6.00=$ \\
\hline $\mathrm{LnOO}$ & 2.16 & $1.95 \pm$ & $3.55 \pm 0.17 \mathrm{a}$ & $2.30 \pm 0.16 b$ & 1.62 & $1.88=$ & $3.85 \pm 0.29 \mathrm{a}$ \\
\hline PLL & $a, b, c$ & 0.48 & $0.82 \pm$ & 0.39 & $0.50 \pm$ & 0.48 & 0.07 \\
\hline LOO & $.14 \mathrm{~b}$ & 16.74 & $16 \mathrm{~b}$ & 21.05 & 12. & 17.15 & 17.2 \\
\hline LOP & b & 10.3 & $0 \mathrm{a}$ & 8.36 & & 7.55 & 14.9 \\
\hline PLP & & $\mathrm{c}$ & 1.9 & & & 0.61 & $.21 \mathrm{a}$ \\
\hline $\mathrm{OOO}$ & $30.08 \pm 1.08 c$ & $31.86 \pm 0.74 c$ & $22.19 \pm$ & $35.18 \pm 0.87 b, c$ & 49.39 & 39.52 & $22.08 \pm 0.67 \mathrm{~d}$ \\
\hline POP & 22.93 & 23.19 & $21.75 \pm 0.90 \mathrm{a}, \mathrm{b}$ & $16.97 \pm 0.59 \mathrm{C}$ & $21.25 \pm$ & 19.93 & 22.10 \\
\hline $\mathrm{POO}$ & & & $a, b$ & & & & $24 \mathrm{a}$ \\
\hline AOL & $0.37 \pm 0.04 b, c, d$ & $0.35 \pm 0.01 c, d$ & $0.18 \pm 0.01 \mathrm{e}$ & $0.48 \pm 0.05 b, c$ & $0.77 \pm 0.03 \mathrm{a}$ & $0.53 \pm 0.04 \mathrm{~b}$ & $0.21 \pm 0.02 \mathrm{~d}$ \\
\hline SOO & $2.92 \pm 0.06 b$ & $4.58 \pm 0.15 a$ & $2.96 \pm 0.18 b$ & $4.36 \pm 0.21 \mathrm{a}$ & $4.69 \pm 0.05 a$ & $4.76 \pm 0.31 \mathrm{a}$ & $3.20 \pm 0.02 b$ \\
\hline SOP & $0.85 \pm 0.05 c$ & $1.30 \pm 0.07 \mathrm{a}$ & $1.03 \pm 0.10 \mathrm{a}, \mathrm{b}, \mathrm{c}$ & $0.85 \pm 0.06 c$ & $0.79 \pm 0.06 c$ & $0.92 \pm 0.05 b, c$ & $1.23 \pm 0.07 a, b$ \\
\hline
\end{tabular}

Mean values in the same row with the same letter are not significantly different between cultivars.

The fatty acid composition is an important parameter in the detection of adulteration, and it has previously been used as a parameter for oil classification $[16,17]$.

As shown in Table 3, oleic (C18:1), linoleic (C18:2), and palmitic (C16:0) acids are the major fatty acids present in the studied olive oils and vary significantly depending on the cultivar $(p<0.05)$. Among the studied olive oils, the Chetoui olive oil has the lowest percentage of palmitic acid $9.39 \%$, and the Coratina olive oil showed the highest percentage of oleic acid (76.79\%) and the lowest percentage of linoleic acid (C18:2) which did not exceed 8\% which may explain this high OS value. Concerning myristic (C14:0), linolenic (C18:3), arachidic (C20:0), heptadecanoic (C17:0), heptadecenoic (C17:1), palmitoleic (C16:1), and stearic (C18: 0 ) fatty acids, the studied olive oil varieties presented low amounts of all of them. The three first ones did not show any significant variation among cultivars; meanwhile, the rest showed very small changes. The data from OS test showed a significant positive correlation with $\mathrm{C} 18: 1$ as reported by Issaoui and coworkers [15]. Peroxide values (IP) presented a negative correlation with $\mathrm{C} 17: 0$ and $\mathrm{C} 16: 0$. In fact, virgin olive oils are known to be more resistant to oxidation than other edible oils because of their contents of natural antioxidants and lower unsaturation levels. These results confirm those reported by Issaoui and coworkers [15]. C14:0 was negatively correlated with OS, $\beta$-carotene, and C18:1 and $\mathrm{K}_{270}$. The triacylglycerols (TAGs) constitute also an authenticity parameter for the differentiation of olive oil from other oils. The presence of a high 1,2,3-trioleylglycerol (OOO) level in olive oil constitutes a favorable authenticity indicator. In Table 4 are given the percentages of the TAGs detected in the analyzed oils. Fifteen TAGs were determined, and their distribution showed significant variation according to the cultivar $(p<0.05)$. The major ones were OOO, POP, LOO, and LOP; their mean values varied from 22.08 (Zalmati) to $49 \%$ (Coratina), 19.93 (Leguim) to $23.19 \%$ (Chemcheli), 12.16 (Coratina) to $21.05 \%$ (Chetoui), and 4.82 (Zalmati) to $14.95 \%$ (Coratina), respectively. Variations in fatty acid composition observed in olive oil samples are related to both genetic factors and environmental conditions during the development and maturation of the fruit. These results are in agreement with the findings of other studies $[2,18]$. Figure 1 showed a highly negative significant correlation between the major TAG OOO and C18:2, C16:1. This TAG presents a negative correlation with IP and free acidity parameters. The TAG LOP is highly correlated with $\mathrm{C} 18: 1$, total phenols, $\beta$-carotene, $\mathrm{K}_{270}$, and OS. However, $\mathrm{K}_{232}$, chlorophyll, $\mathrm{C} 20: 1$, and C18:0 were very poorly correlated with this TAG. The data presented in Figure 1 showed a highly significant negative correlation between LOO and $\mathrm{K}_{232} \mathrm{C} 18: 1$.

The contribution of polyphenols in the olive oil perceptions was reported in several studies. Angerosa and coworkers [19] found that polyphenols contributed to the characterization of walnut husk, bitter and pungent characteristics. Moreover, it was reported that the stimuli that are mainly responsible for bitter and pungent attributes are tyrosol, hydroxytyrosol, and the aglycones that contain them, arising from glycosides naturally occurring in olive fruits $[11,19,20]$.

In our study, the total phenol contents varied significantly among VOO varieties, being Chetoui and Coratina the richest ones (525 and $468 \mathrm{ppm}$, resp.) followed by Chemcheli (354 ppm), which would explain their high resistance to oxidation. Regarding individual phenolic compound in Table 5, we give a list of the detected compounds. Nine phenolic compounds could be identified. The oleuropein aglycone was the major compound followed by its dialdehydic form and the dialdehydic form of ligstroside aglycone. The highest concentration of oleuropein aglycone was registered in Chemcheli oil reaching $60.56 \mathrm{ppm}$. The phenolic alcohols hydroxytyrosol and tyrosol were present at low concentrations and the Chetoui olive oil presented the highest values (2.86 ppm). Tyrosol concentrations were always higher than those of hydroxytyrosol except for the case of Leguim cultivar. Among lignans, pinoresinol and acetoxypinoresinol were identified. The lignan concentration varied between varieties from 0.66 in Zalmati olive oil to $7.32 \mathrm{ppm}$ in Chetoui olive oil (Table 5). Figure 1 showed a negative correlation between phenols and C14:0. 
Table 5: Phenolic composition of the seven VOOs.

\begin{tabular}{lccccccc}
\hline Phenols $(\mathrm{ppm})$ & Arbequina & Chemcheli & Chemleli & Chetoui & Coratina & Leguim & Zalmati \\
\hline Total phenols & $182.54 \pm 11.67 \mathrm{~b}$ & $354.71 \pm 37.89 \mathrm{a}, \mathrm{b}$ & $251.72 \pm 32.25 \mathrm{~b}$ & $525.14 \pm 70.07 \mathrm{a}$ & $468.04 \pm 52.38 \mathrm{a}$ & $245.78 \pm 27.82 \mathrm{~b}$ & $209.55 \pm 25.65 \mathrm{~b}$ \\
Hydroxytyrosl & $0.22 \pm 0.02 \mathrm{a}$ & $0.35 \pm 0.28 \mathrm{a}$ & $0.92 \pm 0.77 \mathrm{a}$ & $0.96 \pm 0.49 \mathrm{a}$ & $0.36 \pm 0.30 \mathrm{a}$ & $1.24 \pm 1.16 \mathrm{a}$ & $0.18 \pm 0.02 \mathrm{a}$ \\
Tyrosol & $1.07 \pm 0.42 \mathrm{a}$ & $2.21 \pm 1.55 \mathrm{a}$ & $1.22 \pm 0.47 \mathrm{a}$ & $1.90 \pm 1.13 \mathrm{a}$ & $1.22 \pm 0.65 \mathrm{a}$ & $0.18 \pm 0.11 \mathrm{a}$ & $0.32 \pm 0.11 \mathrm{a}$ \\
DFOA & $10.17 \pm 0.03 \mathrm{a}$ & $10.21 \pm 0.17 \mathrm{a}$ & $10.78 \pm 0.35 \mathrm{a}$ & $10.34 \pm 0.07 \mathrm{a}$ & $16.39 \pm 6.35 \mathrm{a}$ & $10.39 \pm 0.35 \mathrm{a}$ & $10.30 \pm 0.14 \mathrm{a}$ \\
DFLA & $10.39 \pm 0.18 \mathrm{a}$ & $10.78 \pm 0.40 \mathrm{a}$ & $13.48 \pm 3.32 \mathrm{a}$ & $23.79 \pm 8.95 \mathrm{a}$ & $13.95 \pm 3.47 \mathrm{a}$ & $13.72 \pm 3.52 \mathrm{a}$ & $10.64 \pm 0.38 \mathrm{a}$ \\
$\begin{array}{l}\text { Acetoxypinores } \\
\text { inol }\end{array}$ & $0.40 \pm 0.13 \mathrm{a}$ & $1.04 \pm 0.56 \mathrm{a}$ & $0.09 \pm 0.09 \mathrm{a}$ & $1.57 \pm 0.89 \mathrm{a}$ & $0.82 \pm 0.41 \mathrm{a}$ & $1.48 \pm 0.08 \mathrm{a}$ & $0.09 \pm 0.03 \mathrm{a}$ \\
$\begin{array}{l}\text { Pinoresinol } \\
\text { Elenolic acid }\end{array}$ & $5.76 \pm 2.24 \mathrm{a}$ & $0.64 \pm 0.57 \mathrm{a}$ & $2.37 \pm 1.15 \mathrm{a}$ & $5.75 \pm 1.93 \mathrm{a}$ & $2.58 \pm 2.52 \mathrm{a}$ & $0.73 \pm 0.58 \mathrm{a}$ & $0.57 \pm 0.39 \mathrm{a}$ \\
$\begin{array}{l}\text { Oleuropein } \\
\text { aglycone }\end{array}$ & $1.69 \pm 0.93 \mathrm{a}$ & $2.55 \pm 1.31 \mathrm{a}$ & $0.71 \pm 0.39 \mathrm{a}$ & $2.56 \pm 1.20 \mathrm{a}$ & $1.48 \pm 0.96 \mathrm{a}$ & $0.13 \pm 0.04 \mathrm{a}$ & $2.47 \pm 0.92 \mathrm{a}$ \\
$\begin{array}{l}\text { Ligstroside } \\
\text { aglycone }\end{array}$ & $0.41 \pm 0.06 \mathrm{a}$ & $2.22 \pm 1.44 \mathrm{a}$ & $0.53 \pm 0.35 \mathrm{a}$ & $2.64 \pm 1.58 \mathrm{a}$ & $1.45 \pm 0.77 \mathrm{a}$ & $0.15 \pm 0.09 \mathrm{a}$ & $0.17 \pm 0.06 \mathrm{a}$ \\
\hline
\end{tabular}

Mean values in the same row with the same letter are not significantly different between cultivars.

Polyhenols were also highly negatively correlated with $\mathrm{C} 16: 1$. This result showed that monounsaturated FAs were not influenced by the antioxydant compounds as the polyunsaturated ones (C18:2 and C18:3). Polyphenols were positively correlated with the OS value. This result is in accordance with those previously reported by Abaza and coworkers [1]. From these results, the phenolic content contributed significantly to the stability of virgin olive oils. Phenols, carotenoids, chlorophylls, and FA levels were correlated to OS in different VOOs. These results are in agreement with the study of Issaoui and coworkers [15]. We applied a PCA on the samples VOO cultivars. The cultivar factor variable is considered as a supplementary factor. The 2 spaces defined by the two first principal components explained $54 \%$ of the total variance. Figure 2 represents the circle of correlations of the projection of the variables on the two first principal axes. Figure 3 represents the projection of the seven cultivars in the space defined by the first two principal components. We can then distinguish the presence of three main groups. The first group consisted of the Coratina olive oil. The second group consisted of Arbequina, Zalmati, and Chemlali olive oils. The third one grouped the Chemcheli, Leguim, and Chetoui. The loading plot (Figure 2) of the variables demonstrated that the characteristics of the first group composed of the Coratina olive oil having high oxidative stability, C18:1, AOL and OOO amounts and low amounts of C18: 2, LOO, LLL, LLO, LnLO, LnOO, LnLP, and LOP. The second group is characterized by high amounts of C16:0, C16:1, POP, POO, PLP, SOP, PLL, and LOP and low oxidative stability and low amounts of SOO, C20:1, and phenols. The third group is characterized by high amounts of C18:0, C20:1, SOO, and phenols content and low amounts of SOP, PLL, POP, POO, and C16:1.

\subsection{Preferences according to Consumer Characteristics and} VOOs Cultivars. This section is devoted to the analysis of consumer preferences. In a first step, we present a study of consumer preferences according to consumer characteristics. Secondly, we give a pairwise comparison between the seven tasted cultivars.

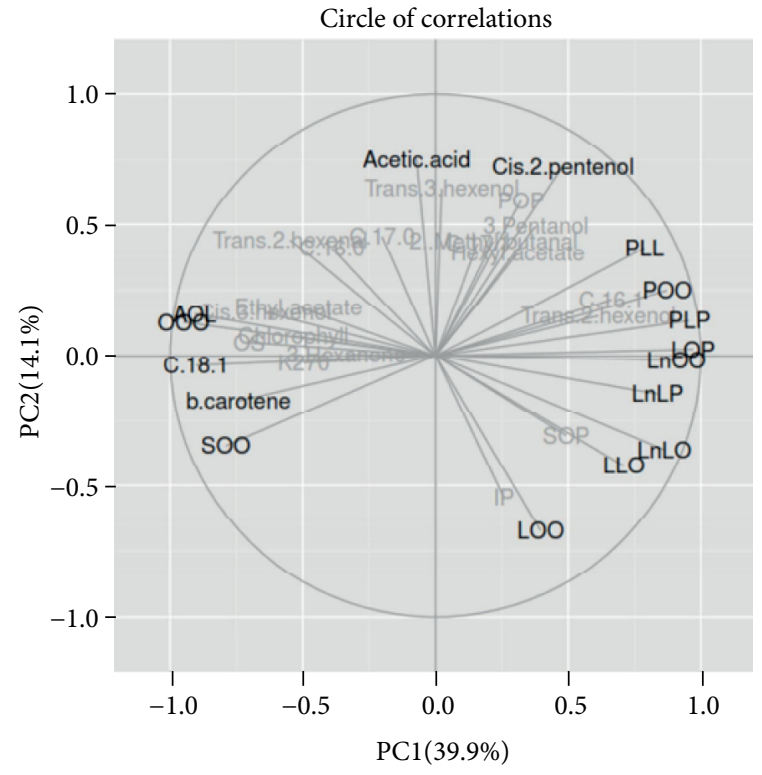

FIgURe 2: Projection of the variables in the space defined by the first two principal components.

4.3. Preferences according to Consumer Characteristics. In this section, we studied the liking of the varieties according to consumer characteristics. We have first used a classical ANOVA approach (Table 6) where the factor variables are age, gender, FC, and RO. This study shows that Chetoui cultivar is significantly preferred by consumers from the South and the Sahel regions compared to the others; this result is in accordance with that of Caporale and coworkers [21]. We observed also that women prefer significantly the Leguim cultivar more than men (Table 6) as reported by Cordelle and coworkers [22]. These results are in agreement with the findings of Caporale and coworkers [21].

4.4. Preferences according to Cultivars. As explained before, the matrix represented in Figure 4 contains the difference $\Delta$ value defined in equation (1) between the number of consumers who prefer significantly the cultivar in the column compared to the one in the row with the number of them 

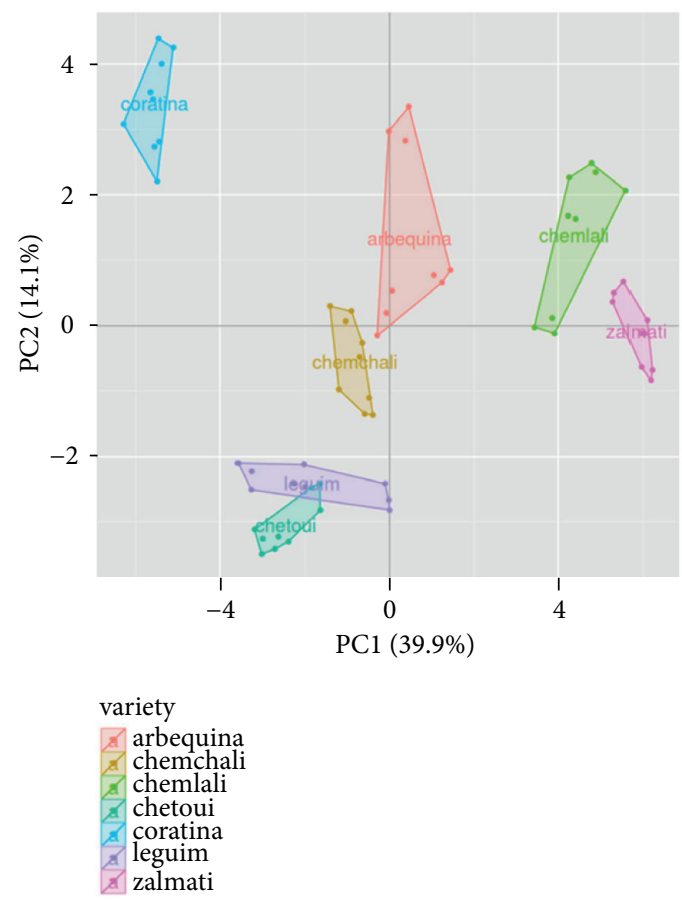

FIgURE 3: Projection of the seven cultivars in the space defined by the first two principal components.

TABLE 6: Results of the ANOVA on mean liking scores.

\begin{tabular}{|c|c|c|c|c|c|c|c|c|}
\hline & \multicolumn{2}{|c|}{ Age } & \multicolumn{2}{|c|}{ Gender } & \multicolumn{2}{|r|}{$\mathrm{FC}$} & \multicolumn{2}{|c|}{$\mathrm{RO}$} \\
\hline \multirow{4}{*}{ Arbequina } & Adults & $11.34(0.24) \mathrm{a}$ & $\mathrm{M}$ & $11.42(0.2) \mathrm{a}$ & 1 & $11.47(0.22) \mathrm{a}$ & Sahel & $11.53(0.32) \mathrm{a}$ \\
\hline & Young & $11.31(0.28) \mathrm{a}$ & $\mathrm{F}$ & $11.03(0.41) \mathrm{a}$ & 3 & $11.06(0.64) \mathrm{a}$ & Center & $11.3(0.54) \mathrm{a}$ \\
\hline & & & & & 2 & $11.06(0.34) \mathrm{a}$ & South & $11.24(0.45) \mathrm{a}$ \\
\hline & & & & & 4 & $9.55(1.55) \mathrm{a}$ & North & $11.2(0.29) \mathrm{a}$ \\
\hline \multirow{4}{*}{ Chemcheli } & Youth & $12.09(0.25) \mathrm{a}$ & $\mathrm{F}$ & $12.19(0.42) \mathrm{a}$ & 4 & $12.4(0.87) \mathrm{a}$ & Sahel & $12.46(0.3) \mathrm{a}$ \\
\hline & Adults & $11.8(0.28) \mathrm{a}$ & M & $11.85(0.21) \mathrm{a}$ & 1 & $11.97(0.23) a$ & South & $11.97(0.51) a$ \\
\hline & & & & & 2 & $11.78(0.38) \mathrm{a}$ & North & $11.75(0.31) \mathrm{a}$ \\
\hline & & & & & 3 & $11.62(0.75) \mathrm{a}$ & Center & $11.17(0.55) \mathrm{a}$ \\
\hline \multirow{4}{*}{ Chemleli } & Youth & $11.89(0.26) \mathrm{a}$ & $\mathrm{F}$ & $11.92(0.37) \mathrm{a}$ & 2 & $12.03(0.45) \mathrm{a}$ & Center & $11.83(0.4) \mathrm{a}$ \\
\hline & Adults & $11.63(0.25) \mathrm{a}$ & $\mathrm{M}$ & $11.7(0.21) \mathrm{a}$ & 4 & 12(1.17)a & Sahel & $11.78(0.31) \mathrm{a}$ \\
\hline & & & & & 3 & $11.87(0.68) a$ & South & $11.71(0.46) \mathrm{a}$ \\
\hline & & & & & 1 & $11.67(0.21) \mathrm{a}$ & North & $11.7(0.32) \mathrm{a}$ \\
\hline \multirow{4}{*}{ Chetoui } & Adults & $11.92(0.27) \mathrm{a}$ & $\mathrm{F}$ & $11.98(0.4) \mathrm{a}$ & 4 & $12.43(1.55) \mathrm{a}$ & South & $12.43(0.54) \mathrm{a}$ \\
\hline & Youth & $11.73(0.28) \mathrm{a}$ & M & $11.79(0.23) \mathrm{a}$ & 2 & $12.08(0.49) \mathrm{a}$ & Sahel & $12.32(0.32) a, b$ \\
\hline & & & & & 1 & $11.95(0.22) \mathrm{a}$ & North & $11.64(0.31) a, b$ \\
\hline & & & & & 3 & $10.06(0.8) \mathrm{a}$ & Center & $10.79(0.54) \mathrm{b}$ \\
\hline \multirow{4}{*}{ Coratina } & Adults & $13.25(0.31) \mathrm{a}$ & $\mathrm{M}$ & $13.27(0.25) \mathrm{a}$ & 4 & $14.45(1.25) \mathrm{a}$ & Center & $13.38(0.62) \mathrm{a}$ \\
\hline & Youth & $13.18(0.31) \mathrm{a}$ & $\mathrm{F}$ & $13.05(0.48) \mathrm{a}$ & 1 & $13.21(0.25) \mathrm{a}$ & Sahel & $13.28(0.36) \mathrm{a}$ \\
\hline & & & & & 3 & $13.19(0.92) a$ & South & $13.18(0.68) a$ \\
\hline & & & & & 2 & $13.06(0.59) \mathrm{a}$ & North & $13.11(0.34) \mathrm{a}$ \\
\hline \multirow{4}{*}{ Leguim } & Youth & $12.48(0.27) \mathrm{a}$ & $\mathrm{F}$ & $13.07(0.34) \mathrm{a}$ & 4 & $13.02(1.54) \mathrm{a}$ & Sahel & $12.79(0.29) \mathrm{a}$ \\
\hline & Adults & $12.06(0.25) \mathrm{a}$ & $\mathrm{M}$ & $12(0.22) b$ & 2 & $12.79(0.48) \mathrm{a}$ & North & $12.2(0.27) \mathrm{a}$ \\
\hline & & & & & 3 & $12.62(0.74) a$ & South & $11.94(0.59) a$ \\
\hline & & & & & 1 & $12.07(0.21) \mathrm{a}$ & Center & $11.43(0.57) \mathrm{a}$ \\
\hline \multirow{4}{*}{ Zalmati } & Youth & $11.87(0.31) \mathrm{a}$ & $\mathrm{F}$ & $11.51(0.42)$ & 2 & $12.33(0.44) \mathrm{a}$ & Sahel & $12.39(0.34) \mathrm{a}$ \\
\hline & Adults & $11.77(0.26) \mathrm{a}$ & $\mathrm{M}$ & $11.9(0.23)$ & 1 & $11.92(0.23) \mathrm{a}$ & Center & $11.86(0.48) \mathrm{a}$ \\
\hline & & & & & 3 & $10.35(0.76) \mathrm{a}$ & South & $11.68(0.51) a$ \\
\hline & & & & & 4 & 9.82(1.62)a & North & $11.33(0.34) \mathrm{a}$ \\
\hline
\end{tabular}

FC: frequency of consumption, RO: region of origin. 


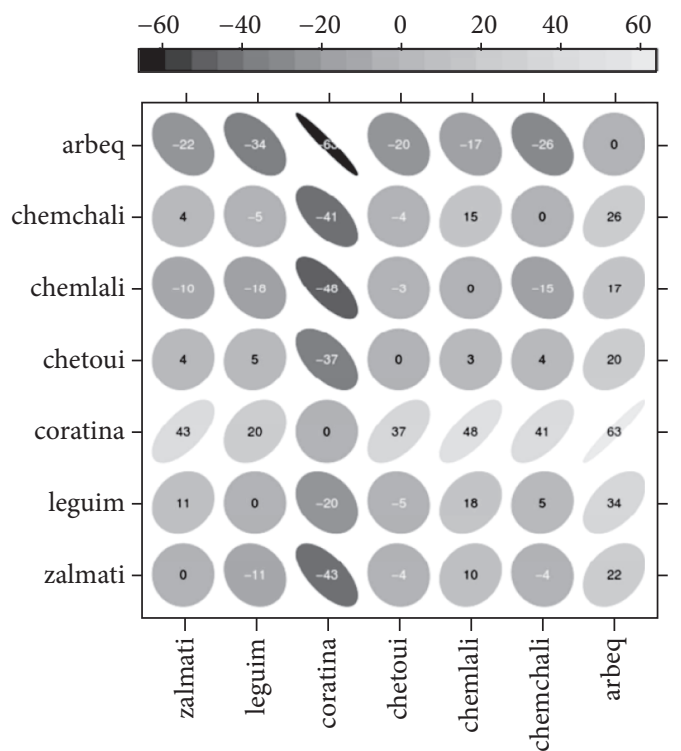

Figure 4: Pairwise comparison between the cultivars.

who prefer the cultivar in row compared to the one in the column. For example, let us observe the column corresponding to VOO Coratina cultivar. All the numbers of this column are negative. We can then conclude that there are always fewer numbers of consumers that prefer the other six cultivars to Coratina. This result would be explained by the particular profile of this $\mathrm{VOO}$ characterized by its richness in polyphenol compounds well known for their role in the sensory attributes of VOO such as bitterness and pungency as reported in literature $[14,16]$ that there are always fewer number of consumers who prefer the other six cultivars to the VOO Coratina. When we observe the row corresponding to Cultivar Leguim that is preferred by the consumers when compared to the cultivars Zalmati, Chemlali, Chemcheli, and Arbequina, only Chetoui and Coratina cultivars are preferred to it. The most unlike VOO cultivar seems to be Arbequina since the corresponding entries in the Arbequina row are all negative. Arbequina $\mathrm{VOO}$ was characterized by a high amount of C16:0 responsible for VOO figeability low OS, and low amount of phenols (Figure 4) responsible for VOO bitterness and pungency. This result explains that the consumer does not prefer sweet and rigid oil.

In this paper, we have proposed a new approach for studying consumer preferences when the number of the tasted products by our consumers is low. Indeed, two hundred and seventy-four consumers tasted six times EVOO products from seven varieties (Arbequina, Chemcheli, Chemlali Chetoui, Leguim, Zalmati, and Coratina). Each product corresponds to one cultivar. We have also made a physicochemical analysis of these products and we aim to analyze consumer preference in terms of these physicochemical parameters. Since the number of the products is low, any classical consumer preference method such as internal or external preference mapping is impossible to use; we have then suggested a new approach based on comparing each pair of cultivars by making simple linear regression analysis where the response variable is the scores given by each consumer and the explained variable is the "cultivar" and we were only interested in the sign of the significant $\beta$-coefficients. The result of this method showed that Coratina olive oil is the most preferred product, Chetoui is the second, and Leguim is the third. By corresponding the projections of the cultivars using consumer preference and physicochemical parameters, variables such as total phenols, carotene, chlorophylls, C16:0, C16:1, C17:0, C17:1, C18: 0 , C18:1, C18:2, C20:1, and TAG composition may explain the consumer preference. In fact, the Coratina olive oil is rich in total phenols and oleic acid with a low amount of chlorophylls and carotene. Studying the sensorial profile of the olive oils in order to find out its role in the determination of consumer preference and exploring the capability of consumer to evaluate the sensory attributes of the VOOs compared to a panel of experts would be of great interest to justify these present findings.

\section{Abbreviations}

Fatty acids (FAs)

C14:0: Myristic acid

C16:0: Palmitic acid

C16:1: Palmitoleic acid

C17:0: Heptadecanoic acid

C17:1: Heptadecenoic acid

C18:1: Oleic acid

C18:2: Linoleic acid

C18:3: Linolenic acid

C20 : 0: Arachidic acid

20:1: Gondoic acid (11-eicosenoic acid)

Triacylglycerols (TAGs)

O: Oleic acid

L: $\quad$ Linoleic acid

P: $\quad$ Palmitic acid

S: $\quad$ Stearic acid

Ln: Linolenic acid

IP: $\quad$ Peroxide value

O.S: Oxidative stability

DFOA: Dialdehydic form of oleuropein aglycone

DFLA: Dialdehydic form of ligstroside aglycone

FC: $\quad$ Frequency of consumption

RO: Region of origin

IOC: International olive oil

ISO: International Organization for Standardization

PCA: Principal component analysis

VOO: Virgin olive oil

FID: Flame ionization detector.

\section{Data Availability}

The data are available upon request to the first author Dr. Kaouther Ben-Hassine (kaoutheragro@yahoo.fr).

\section{Conflicts of Interest}

The authors declare that they have no conflicts of interest regarding the publication of this paper. 


\section{Acknowledgments}

The authors are grateful to Société des Huileries Vitoni Barri, Pieralisi Italy, Huilerie Slema Frères, Magazin Général and Huilerie Sadira, and Huilerie du Nord Tourkhani.

\section{References}

[1] S. Dabbou, M. Issaoui, M. Servili et al., "Characterisation of virgin olive oils from European olive cultivars introduced in Tunisia," European Journal of Lipid Science and Technology, vol. 111, no. 4, pp. 392-401, 2009.

[2] N. G. Kammoun and W. Zarrouk, "Exploratory chemometric analysis for the characterisation of Tunisian olive cultivars according to their lipid and sterolic profiles," International Journal of Food Science and Technology, vol. 47, no. 7, pp. 1496-1504, 2012.

[3] International Olive Council, "Analyse sensorielle de l'huile d'olive. Norme guide pour l'installation d'une salle de dégustation," COI/T.20/Doc. $N^{\circ}$ 6/Rev, vol. 1, 2007.

[4] ISO 660 and International Norm, Animal and Vegetable Fats and oils, Determination of Acid Value and Acidity, ISO, Geneva, Switzerland, 1996.

[5] ISO3960 and International Norm, Animal and Vegetable Fats and oils, Determination of Peroxide Value, ISO, Geneva, Switzerland, 2001.

[6] International olive Council, "Trade standard applying to olive oils and olive-pomace oils," Resolution, vol. 2, pp. 1-16, 2006.

[7] F. Gutierrez Rosales, "Determinación de La estabilidad oxidativa de Aceites de Oliva vírgenes: comparación entre el método del oxigeno activo (A.O.M.) y el método rancimat," Grasas Y Aceites, vol. 40, pp. 1-5, 1989.

[8] M. Isabel Minguez-Mosquera, L. Rejano-Navarro, B. GandulRojas, A. H. SanchezGomez, and J. Garrido-Fernandez, "Color-pigment correlation in virgin olive oil," Journal of the American Oil Chemists Society, vol. 68, no. 5, pp. 332-336, 1991.

[9] S. Dabbou, I. Rjiba, A. Nakbi, N. Gazzah, M. Issaoui, and M. Hammami, "Compositional quality of virgin olive oils from cultivars introduced in Tunisian arid zones in comparison to chemlali cultivars," Scientia Horticulturae, vol. 124, no. 1, pp. 122-127, 2010.

[10] M. Issaoui, B. Mechri, A. Echbili et al., "Chemometric characterization of five Tunisian varietals ofolea europaeal. Olive fruit according to different maturation indices," Journal of Food Lipids, vol. 15, no. 3, pp. 277-296, 2008.

[11] G. Montedoro, M. Servili, M. Baldioli, and E. Miniati, "Simple and hydrolyzable phenolic compounds in virgin olive oil. 1. Their extraction, separation, and quantitative and semiquantitative evaluation by HPLC," Journal of Agricultural and Food Chemistry, vol. 40, no. 9, pp. 1571-1576, 1992.

[12] P. Schlich, "Preference mapping: relating consumer preferences to sensory or InstrumentalMeasurements," in Bioflavour'95. Analysis/precursor Studies/biotechnology, pp. 231-245, INRA, Versailles, France, 1995.

[13] J. A. McEwan, "Preference mapping for product optimization," in Multivariate Analysis of Data in Sensory Science, T. Naes and E. Risvik, Eds., Elsevier Science, Amsterdam, pp. 71-102, 1996.

[14] C. Benincasa and K. Ben Hassine, "Volatile and non-volatile compounds of single cultivar virgin olive oils produced in Italy and Tunisia with regard to different extraction systems and storage conditions," in Oive Oil-Constituents, Quality,
Health Properties and Bioconversions, D. Boskou, Ed., InTech, 2012.

[15] M. Issaoui, S. Dabbou, F. Brahmi, K. B. Hassine, M. H. Ellouze, and M. Hammami, "Effect of extraction systems and cultivar on the quality of virgin olive oils," International Journal of Food Science and Technology, vol. 44, no. 9, pp. 1713-1720, 2009.

[16] A. B. Mansour, B. Gargouri, G. Flamini, and M. Bouaziz, "Effect of agricultural sites on differentiation between chemlali and neb jmel olive oils," Journal of Oleo Science, vol. 64, no. 4, pp. 381-392, 2015.

[17] B. Gargouri, S. Ammar, A. Ben Mansour, and B. Mohamed, "Effect of growing region on quality characteristics and phenolic compounds of chemlali extra-virgin olive oils," J. acta physiol plant., 2013.

[18] F. M. Haddada, H. Manai, D. Daoud, X. Fernandez, L. Lizzani-Cuvelier, and M. Zarrouk, "Profiles of volatile compounds from some monovarietal Tunisian virgin olive oils. Comparison with French PDO," Food Chemistry, vol. 103, no. 2, pp. 467-476, 2007.

[19] F. Angerosa, N. d'Alessandro, P. Konstantinou, and L. Di Giacinto, "GC-MS evaluation of phenolic compounds in virgin olive oil," Journal of Agricultural and Food Chemistry, vol. 43, no. 7, pp. 1802-1807, 1995.

[20] R. Ben Hmida, N. Frikha, S. Bouguerra Neji, G. Kit, F. Medina, and M. Bouaziz, "Synthesis of high added value compounds through catalytic oxidation of 2-phenylethanol: a Kinetic study," International Journal of Chemical Kinetics, vol. 1-10, 2019.

[21] G. Caporale, S. Policastro, A. Carlucci, and E. Monteleone, "Consumer expectations for sensory properties in virgin olive oils," Food Quality and Preference, vol. 17, no. 1-2, pp. 116-125, 2006.

[22] S. Cordelle, C. Lange, and P. Schlich, "On the consistency of liking scores: insights from a study including 917 consumers from 10 to 80 Years old," Food Quality and Preference, vol. 15, no. 7-8, pp. 831-841, 2004. 